\title{
Psychocardiology: the spectrum of stress in the genesis of heart disease: a point of view
}

This article was published in the following Dove Press journal:

Research Reports in Clinical Cardiology

8 August 2013

Number of times this article has been viewed

\section{Horst J Koch}

Department of Psychiatry and Psychotherapy, HELIOS Clinic Aue Academic Hospital of the Technical University Dresden, Aue, Germany
Correspondence: Horst J Koch Department of Psychiatry and Psychotherapy, HELIOS Clinic Aue Academic Hospital of the Technical University Dresden, Gartenstraße 6, D-08280 Aue, Germany Tel +4903 77I 58I 509

Email horst.koch@helios-kliniken.de
Abstract: Psychiatric disease, particularly depression and stress disorders, worsens the outcome of cardiovascular disease by about a factor of two to three. Conversely, heart disease can also cause or aggravate affective disorders in the person concerned. Although this mind-heart interaction has been known since the 1930s, many questions about the underlying mutual pathophysiology remain. Apart from psychological stress models, inflammatory or psychoimmunology processes and metabolic or endocrinological mechanisms may be involved, as might lifestyle and drug treatments. Takotsubo, or broken-heart cardiomyopathy, which frequently occurs in response to stressful events, and post-myocardial infarction depression may serve as paradigms in seeking to understand the pathological basis of the mind-heart relationship.

Keywords: broken-heart cardiomyopathy, takotsubo, post-infarction depression, mind-heart interaction, pathophysiology

\section{Introduction}

There is no doubt that psychiatric syndromes such as depression, stress disorders and schizophrenia increase the risk of heart and cardiovascular disorders such as coronary heart disease, with odds ratios of 1.5 to 2.7 reported for depression in epidemiological studies. ${ }^{1}$ As a consequence, the clinical outcomes can be worse, and this corresponds to increased mortality. ${ }^{2-6}$ This important negative impact of depression on mortality has been known since $1937 .^{7}$ A recent study of more than 4000 patients suffering from depression and myocardial infarction found that, if not treated adequately, the depression tripled patients' risk of dying following heart attack. ${ }^{8}$ Similarly, anxiety spectrum disorders (eg, panic disorder, post-traumatic stress disorder, generalized anxiety) - both with and without depressive symptoms - significantly increase the risk of heart attack. ${ }^{9}$ The psycho-cardiovascular interaction is reciprocal; that is, psychiatric disorders deteriorate cardiovascular disease and vice versa. Two extreme examples of such mind-heart interactions are "takotsubo," or broken-heart syndrome, and post-myocardial infarction depression.

The mind-heart interaction - the relationship between the heart and the mind - is complex and far from being completely understood. Hypothetical pathophysiological mediating links may help to approach the problem, but one should be very cautious to explain individual disorders by means of these hypothetical models. Some of these plausible and helpful hypotheses are summarized in Table 1. It is not possible to ascertain and distinguish pathophysiological associations for each individual, as every patient has their own medical history and diagnostic findings must be evaluated for each patient. Hence, physicians should strive for individual medical 


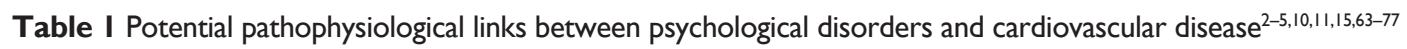

\begin{tabular}{|c|c|}
\hline Etiological factor & Associated mechanisms \\
\hline Transient insulin resistance & Hypercortisolemia during depression, increased risk of developing diabetes \\
\hline Visceral overweight & Diabetes, MS, hypercortisolemia \\
\hline Arterial hypertonia & $\begin{array}{l}\text { Overweight, diabetes, "vascular depression" (association between MS and } \\
\text { depression) }\end{array}$ \\
\hline Low birth weight & Depression, heart disease, possibly mediated by programming the HPA-axis \\
\hline Metabolic syndrome & Lifestyle, nutrition, medication (eg, antipsychotics, antidepressants) \\
\hline Hyperlipidemia & $\begin{array}{l}\text { High TGL, low HDL during depression, suicide and possibly hypocholesterinemia, } \\
\text { vascular depression }\end{array}$ \\
\hline Reduced MTHFR activity & Depression, hyperhomocysteinemia, possibly dementia \\
\hline Serotonin transporter polymorphism & Depression, increased platelet function and cardiovascular risk \\
\hline Norepinephrine transporter & $\begin{array}{l}\text { Reduced function in heart failure and possible involvement in depression (particularly } \\
\text { anhedonia) }\end{array}$ \\
\hline Autonomic dysregulation & $\begin{array}{l}\text { Increased sympathetic tone with tachycardia, reduced heart rate variability, risk of } \\
\text { arrhythmia, increased QT variability }\end{array}$ \\
\hline Endocrinology & Activation of HPA axis (hypercortisolemia, stress), hypothyreosis \\
\hline Lack of omega-3 fatty acids & Unbalanced diet, lifestyle \\
\hline Inflammation & CRP, IL-6, TNF- $\alpha$, viral disease, PNI, cholinergic anti-inflammatory reflex \\
\hline Reactive oxygen species & Calcium homeostasis and contractile dysfunction, cellular damage \\
\hline Drugs & $\begin{array}{l}\text { Weight, MS, diabetes, depletion of neurotransmitter stores, hypertonia, risk of } \\
\text { bleeding (SSRIs can cause gastrointestinal bleeding) }\end{array}$ \\
\hline Compliance/Lifestyle & General risk, self-medication, addiction, lack of training, smoking habits \\
\hline Pain localization and perception and focus of attention & Syndrome $X$ (angina with normal coronary vessels), panic attacks \\
\hline Cardiological interventions & Anxiety (especially during procedure), unrealistic expectations (cognitive dissonance) \\
\hline
\end{tabular}

Abbreviations: CRP, C-reactive protein; HDL, high-density lipoprotein; HPA, hypothalamic-pituitary-adrenal; IL, interleukin; MS, metabolic syndrome; MTHFR, methylene tetrahydrofolate reductase; PNI, psychoneuroimmunology; SSRIs, selective serotonin reuptake inhibitors; TGL, triglyceride; TNF- $\alpha$, tumor necrosis factor-alpha.

and psychotherapeutic approaches. However, Bradford Hill causation criteria may be substantiated epidemiologically for most of the suggested etiological mechanisms. ${ }^{5,10}$

In everyday psychiatric practice, we have to deal with electrocardiography (ECG), clinical laboratory results, and weight control, particularly to safeguard drug treatment and improve patient compliance. In addition, we are regularly asked to consult in case of palpitations and/or reasonable suspicion of somatization. Mind-heart interaction really starts prior to evident cardiovascular or psychiatric disease. Patients with anxiety, depression, and/or corresponding personality disorders tend to be worried about heart attacks and/or pain. ${ }^{11}$ Herrmann-Lingen and Buss ${ }^{12}$ showed that anxiety, depression, and Type D personality (ie, chronic depressive mood) are associated, with physiological and psychological patho-mechanisms (eg, the autonomous nervous system, the endocrine system) being etiologically important. In contrast, Myrtek ${ }^{13}$ determined that Type A behavior (ie, competitive drive, enhanced aggressiveness, impatience, and sense of time urgency) is not - as could be prima facie expected - a relevant risk factor for coronary heart disease compared with Type B behavior (relaxed and less hurried). In fact, Type A behavior is slightly protective against heart disease, as it corresponds with an active lifestyle with many fewer risk factors such as obesity and smoking. Finally, it should not be forgotten that modern cardiological diagnostic and interventional procedures, although absolutely beneficial, may cause patients anxiety and some kind of cognitive dissonance or disappointment due to unrealistic expectations. ${ }^{14}$

One interesting mechanism of mind-heart interaction in chronic heart failure is psychoneuroimmunology, particularly the so-called cholinergic anti-inflammatory reflex. ${ }^{15}$ Cytokines such as interleukin 6 can stimulate the sympathetic nervous system and are increased at times of stress; this rise in cytokines correlates to ventricular dysfunction. In contrast, cholinergic activity reduces this negative escalation, and - mediated via feedback loops - the cytokines stimulate parasympathetic outflow, leading to a decelerated inflammation process. ${ }^{16}$ Reactive oxygen species are also discussed in this regard, both in cardiac and psychiatric disorders. ${ }^{17,18}$ Epigenetic phenomena are another exciting field of future research in this respect; these are involved in the pathology of both psychiatric and cardiac diseases and may be an additional link in the mind-heart interaction. ${ }^{19,20}$ Generally, DNA methylation, histone modification and micro-RNA alterations respond rapidly to environmental stress, both in neuropsychiatric and cardiovascular disorders. 


\section{Takotsubo cardiomyopathy, or broken-heart syndrome, as a paradigm of mind-heart interaction}

Although much has been learned about the relationship between psychiatric disorders or stress and heart disease, it is difficult to discern underlying pathophysiological factors, and sometimes such investigation proves fruitless. Takotsubo cardiomyopathy (and post-myocardial infarction depression, which is discussed further on) may serve as a pathophysiological paradigm to determine physiological mechanisms.

Broken-heart syndrome (also called "stress-induced" or "ampulla" cardiomyopathy) was first characterized in Japan roughly 20 years ago by Sato et $\mathrm{al}^{21}$ and Dote et al..$^{22}$ In a population admitted to hospital due to risk of myocardial infarction, $7 \%$ to $8 \%$ may show takotsubo-like symptoms. ${ }^{23}$ The typical patient, frequently a postmenopausal woman, is referred to the cardiological department due to strong suspicion of myocardial infarction (ST-elevation) or acute coronary syndrome without concomitant stenosis and - at the most - slight elevation of the cardiac laboratory panel. The term "takotsubo" is from the Japanese word for a pot with a bottleneck to catch cuttlefish. The syndrome is defined by left-sided or biventricular apical akinesia with dynamic outflow obstruction. Clinically, angina pectoris, systolic heart murmur, cardiac failure, and arrhythmia may dominate the findings. ${ }^{24-29}$ Embolic events, heart failure, or ventricular wall damage may occur and worsen the outcome. Standard diagnostic procedures (ie, ECG, clinical laboratory tests, echocardiography, coronary angiography, and possibly cardiac nuclear magnetic resonance imaging) have to be done to confirm the diagnosis.

As a rule, intense, mostly emotional - occasionally somatic - stress precedes the acute disorder, which leads to acute adjustment disorder with anxious-depressive symptoms or occasionally panic-like attacks with hyperventilation. ${ }^{30-33}$ The syndrome requires an interdisciplinary approach, with treatment of both the heart failure and psychiatric disorder. First, until takotsubo is confirmed, patients should be treated for myocardial infarction to avoid tissue damage. Platelet aggregation inhibitors (eg, acetylsalicylic acid) and, if necessary, anticoagulants (eg, heparin, warfarin) are recommended. ${ }^{34}$ Beta-blockers should reduce sympathetic tone and can be used with acetylsalicylic acid for maintenance treatment. Angiotensin-converting enzyme inhibitors or angiotensin II receptor type 1 antagonists are indicated for left-ventricular dysfunction and may be supplemented by aldosterone antagonists later on. Of course, in the case of severe heart failure, intensive care unit therapy, including the use of intra-aortal pumps, is indicated. Beta-agonists, nitrates, methylxanthines, sotalol, or amiodarone should be administered with caution, due to increased sympathetic tone or possible QTc-interval prolongation. ${ }^{25,34}$

\section{Pathophysiological model of takotsubo cardiomyopathy}

The exact pathophysiology underlying broken-heart syndrome is not known, but most clinicians speculate that spasms of epicardial coronary vessels, impaired microcirculation or overstimulation of the heart due increased catecholamine levels could cause the cardiomyopathy. ${ }^{22,24,32,35,36}$ The common underlying psychological factor is stress, with activation of the hypothalamic-pituitary-adrenal axis and hypercortisolemia. Indeed, catecholamine levels are raised by a factor of two to three..$^{32}$ In addition, hormonal balance or fatty acid metabolism may play an etiological role..$^{35,37}$

In this context, one should not forget that catecholamine activity is not uniformly distributed in the heart muscle. Indeed, noradrenaline infusions in dogs have shown a gradient of activity, from the base (high) towards the apex (low), corresponding to an analog innervations pattern, and the density of beta-receptors decreases from apex to base..$^{38-40}$ Following adrenaline infusion, the overall contractility is more pronounced in the apex. If we consider the heart as being an inverted cone, we can derive from the (simplified) Laplace law (wall tension $\approx$ transmural pressure $\times$ radius) that the effect of catecholaminergic overstimulation may be emphasized in the apical region, ${ }^{41}$ which favors myocardial hypoxia - or an increase of oxygen demand - in the apex. This lack of oxygen may hence be responsible for the wall dyskinesia. As we know that depression causes stress in the body, with increased levels of cortisol and catecholamines, ${ }^{42}$ stress-hormone flooding - subjective sadness is more important than the objective impact of the event - may explain the pathophysiology of broken-heart syndrome.

\section{Post-myocardial infarction depression}

Lett and colleagues ${ }^{43}$ found that patients who develop a post-myocardial infarction depression are up to eight times more likely to experience complications and/or to die. Surprisingly, the severity of the depressive syndrome itself does not substantially influence the outcome and quality of life of persons concerned. ${ }^{44}$ Indeed, even a slight depressive mood may impair the rehabilitation process and well-being 
of the patient. Other studies have estimated the increased order of risk of mortality following myocardial infarction due to depression to be 1.5 to $3.0 .^{45,46}$

Post-myocardial infarction depression is observed in roughly $10 \%$ of patients, almost $40 \%$ of whom suffer depressive symptoms corresponding to Becks Depression Inventory scores greater than $10 .{ }^{47}$ In most affected patients, the link between depression and worsened outcome of myocardial infarction is considered to be a psychological one, due to lack of vitality, stress due to diagnosis or treatment, and bereavement. ${ }^{48,49}$ Somatic complaints associated with depression appear to play a decisive role in the course of the infarction. ${ }^{50}$ Further mechanisms, such as metabolic factors or cytokines, may also be involved but remain to be elucidated.

\section{General aspects of psychiatric pharmacotherapy in patients with concomitant cardiovascular disease}

Although the author considers psychological support essential in case of myocardial infarction, only slight evidence exists for psychotherapeutic approaches. ${ }^{51,52}$ Moreover, in everyday practice, psychological services may be unavailable, although, if this is the case, they should be strived for in future. Of course, cardiologists should be trained to detect depressive mood and seek specialist help when it is noted, but unfortunately, long-term psychotherapies, which are certainly effective in the long run, cannot be carried out in intensive care units. However, a list of nearby psychotherapists should be kept at hand.

This section of the article focuses on pharmacological treatment, which should, of course, be incorporated into a good, communicative doctor-patient relationship. As physicians, we should never forget that it is better to prevent diseases by means of integrated lifestyle change programs than to correct lifestyle peccadilloes after onset of disease. ${ }^{53}$ This insight holds for both affective and cardiological disorders.

The principles of cardiological treatment for takotsubo cardiomyopathy have been outlined in the previous section. However, treatment of simultaneous psychiatric disorders is mandatory to improve the outcome. There is no general treatment plan, as each case requires an individual approach, but individual aspects with regard to entity (eg, brokenheart syndrome, post-myocardial infarction depression), concomitant disease(s) (eg, diabetes, stroke), and severity (acute, chronic) must be considered. It would be foolhardy to insist on an active lifestyle, normal weight, and a mixed diet rich in vitamins and unsaturated and/or omega-3 fatty acids if acute crisis intervention is indicated and, depending on the triggering factors, long-term psychotherapeutic care apart from medical intervention may be required. To objectively check the balance between the risk of adverse events and the risk of depression, one must keep in mind that antidepressant drugs - irrespective of class - improve the outcome and reduce overall mortality in myocardial infarction. ${ }^{54}$ It is therefore wise to realistically discuss the issue with the patient or their attorney.

If antidepressant treatment should be necessary, selective serotonin reuptake inhibitors (eg, sertraline, citalopram) compounds that also have some platelet anti-aggregating effects - are said to be safe and effective. ${ }^{55-57}$ Although safe with regard to cardiovascular disease, paroxetine (which has a half-life of about 16 hours) and fluoxetine (which has a half-life of about 5 days) may cause more pharmacological interactions - most important inhibition of CYP2D6 mostly in elderly patients treated with polypharmacy. Mirtazapine, which has low risk of interaction, may be an alternative and patients may welcome its sleep-inducing effect. However, weight gain and glucose tolerance should be checked regularly and could in some patients limit its use. ${ }^{58}$ Of course, regular ECG recordings (QTc-time) and tests of serum electrolytes (magnesium, sodium, potassium) should be part of the psycho-cardiovascular laboratory panel to minimize the risk of arrhythmia, which is low with therapeutic doses.

Drugs with noradrenergic mechanisms (eg, venlafaxine, bupropion, reboxetine) as well as the reversible monoamineoxidase inhibitor moclobemide are prone to increase blood pressure, although the risk must be weighed against the clinical benefit. ${ }^{59,60}$ (Irreversible inhibitors such as tranylcypromine may not be suited due to the necessity of low tyramine diet.) Reboxetine, in particular, although possibly effective in post-myocardial infarction depression and which has low interaction potential, is no longer considered a firstchoice drug. Regardless, regular blood pressure monitoring is advisable. Should antipsychotics be necessary - for example, in depression with paranoid symptoms - the lowest possible dose should be strived for. To date, the lowest risk with regard to metabolic syndrome or propensity towards ECG changes is carried by aripiprazole or asenapine. ${ }^{61,62}$ However, the risk of QTc-prolongations is lower than $0.05 \%$ in patients receiving therapeutic doses of risperidone, quetiapine, amisulpride, or olanzapine. ${ }^{57}$ This risk may be manageable in clinical practice provided regular clinical laboratory tests and ECG recordings are warranted. 


\section{Conclusion}

Mutual mind-heart interaction has a critical impact on the course of both cardiological and affective disorders. The treatment of depression or related syndromes improves the outcome of myocardial infarction or heart failure and saves lives, while good cardiovascular condition minimizes the risk of stress-induced affective disorders. We are beginning to understand the underlying pathophysiological common mechanisms involved, which may provide further approaches with regard to treatment and prevention of mindheart disorders.

\section{Disclosure}

The author declares no conflicts of interest in this work.

\section{References}

1. Steptoe A. Depression and the development of coronary heart disease. In: Steptoe A, editor. Depression and Physical Illness. Cambridge: Cambridge University Press; 2007:53-86.

2. Rugulies R. Depression as a predictor for coronary heart disease. a review and meta-analysis. Am J Prevent Med. 2002;23(1):51-61.

3. van Melle JP, de Jonge P, Spijkerman TA, et al. Prognostic association of depression following myocardial infarction with mortality and cardiovascular events: a meta-analysis. Psychosom Med. 2004;66(6):813-822.

4. Glassman A. Depression and cardiovascular disease. Pharmacopsychiatry. 2008;41(6):221-225.

5. Glassman AH, Bigger JT Jr, Gaffney M. Psychiatric characteristics associated with long-term mortality among 361 patients having an acute coronary syndrome and major depression: seven-year follow-up of SADHART participants. Arch Gen Psychiatry. 2009;66(9):1022-1029.

5. Herrmann-Lingen Ch, Albus Ch, Titscher G. Psychokardiologie. Ein Praxisleitfaden für Ärzte und Psychologen. Deutscher Ärzteverlag, Köln 2008.

7. Malzberg B. Mortality among patients with involution melancholia. Am J Psychiatry. 1937;93(5):1231-1238.

8. Scherrer JF, Chrusciel T, Garfield LD, et al. Treatment-resistant and insufficiently treated depression and all-cause mortality following myocardial infarction. Br J Psychiatry. 2012;200(2):137-142.

9. Scherrer JF, Chrusciel T, Zeringue A, et al. Anxiety disorders increase risk for incident myocardial infarction in depressed and nondepressed Veterans Administration patients. Am Heart J. 2010;159(5):772-779.

10. Ladwig KH, Lederbogen F, Völler H, et al. Positionspapier zur Bedeutung von psychosozialen Faktoren in der Kardiologie [Position paper on the importance of psychosocial factors in cardiology]. Kardiologie. 2008;2(4):274-287. German.

11. Laederach-Hofmann K, Messerli-Buergy N. Chest, pain, angina pectoris, panic disorder, and syndrome X. In: Jordan J, Bardé B, Zeiher AM, editors. Contributions Toward Evidence-Based Psychocardiology: A Systematic Review of the Literature. Washington DC: American Psychological Association; 2006:185-206.

12. Herrmann-Lingen C, Buss U. Anxiety and depression in patients with coronary heart disease. In: Jordan J, Bardé B, Zeiher AM, editors. Contributions Toward Evidence-Based Psychocardiology: A Systematic Review of the Literature. Washington DC: American Psychological Association; 2006:125-157.

13. Myrtek M. Type A behaviour and hostility as independent risk factor for coronary heart disease. In: Jordan J, Bardé B, Zeiher AM, editors. Contributions Toward Evidence-Based Psychocardiology: A Systematic Review of the Literature. Washington DC: American Psychological Association; 2006:159-183.
14. Jordan J, Lazanowksi C. Psychosocial aspects of coronary catheterization, angiography, and angioplasty. In: Jordan J, Bardé B, Zeiher AM, editors. Contributions Toward Evidence-Based Psychocardiology: A Systematic Review of the Literature. Washington DC: American Psychological Association; 2006:207-229.

15. Emani S, Binkley PF. Mind-body medicine in chronic heart failure: a translational science challenge. Circ Heart Fail. 2010;3(6):715-725.

16. Tracey KJ. The inflammatory reflex. Nature. 2002;420(6917): 853-359.

17. Bilici M, Efe H, Köroğlu MA, Uydu HA, Bekaroğlu M, Değer O Antioxidative enzyme activities and lipid peroxidation in major depression: alterations by antidepressant treatments. J Affect Disord. 2001;64(1):43-51.

18. Naviaux RK. Oxidative shielding or oxidative stress? J Pharmacol Exp Ther. 2012;342(3):608-618.

19. Abdomaleky HM, Thiagalingam S, Wilcox M. Genetics and epigenetics in major psychiatric disorders: dilemmas, achievements, applications, and future scope. Am J Pharmacogenomics. 2005;5(3):149-160.

20. Ordovás JM, Smith CE. Epigenetics and cardiovascular disease. Nat Rev Cardiol. 2010;7(9):510-519.

21. Sato H, Tateishi H, Uchida T, et al. Takotsubo type cardiomyopathy due to multivessel spasm. In: Kodama K, Haze K, Hon M, editors. Clinical Aspect of Myocardial Injury: From Ischemia to Heart Failure. Tokyo: Kagakuhyoronsha; 1990:56-64. Japanese.

22. Dote K, Sato H, Tateishi H, Uchida T, Ishihara M. Myocardial stunning due to simultaneous multivessel coronary spasms: a review of 5 cases. J Cardiol. 1991;21(2):203-214. Japanese.

23. Wedekind H, Möller K, Scholz KH. Tako-Tsubo-Kardiomyopathie. Inzidenz bei Patienten mit akutem Koronarsyndrom [Tako-tsubo cardiomyopathy. Incidence in patients with acute coronary syndrome.] Herz. 2006;31(4):339-346. German.

24. Arora S, Alfayoumi F, Srinivasan V. Transient left ventricular apical ballooning after cocaine use: is catecholamine cardiotoxicity the pathologic link? Mayo Clinic Proc. 2003;81(6):829-832.

25. Bybee KA, Kara T, Prasad A, et al. Systematic review: transient left ventricular apical ballooning: a syndrome that mimics ST-segment elevation myocardial infarction. Ann Intern Med. 2004;141(11):858-865.

26. Goldstein DS, Holmes C, Frank SM, et al. Cardiac sympathetic dysautonomia in chronic orthostatic intolerance syndromes. Circulation. 2002;106(18):2358-2365.

27. Saurer G, Weihs W. Transient left ventricular apical ballooning syndrome (Tako-Tsubo-Kardiomyopathie) - ein Fallbericht. Austrian Journal of Cardiology. 2006;13(11-12):383-385. German.

28. Koch HJ, Ketteler T, Dirsch R. Takotusbo-Kardiomyopathie bei einer 83-jährigen Witwe [Takotsubo cardiomyopathy in a 83-year old women]. MMW Fortschr Med. 2010;152:41-42.

29. Chandrasegaram MD, Celermajer DS, Wilson MK. Apical ballooning syndrome complicated by acute severe mitral regurgitation with left ventricular outflow obstruction - case report. J Cardiothorac Surg 2007;2:14.

30. Girod JP, Messerli AW, Zidar F, Tang WH, Brener SJ. Images in cardiovascular medicine. Tako-tsubo - like transient left ventricular dysfunction. Circulation. 2003;107(18):e120-e121.

31. Brandspiegel HZ, Marinchak RA, Rials SJ, Kowey PR. A broken heart. Circulation. 1998;98(13):1349.

32. Wittstein IS, Thielmann DR, Lima JA, et al. Neurohumoral features of myocardial stunning due to sudden emotional stress. N Engl J Med. 2005;352(6):539-548.

33. Desmet WJ, Adriaenssens BF, Dens JA. Apical ballooning of the left ventricle: first series in white patients. Heart. 2003;89(9):1027-1031.

34. Said SM, Albouaini K, Herold J, et al. Takotsubo syndrome from original description up to now. Med Klin (Munich). 2009;104(6): 434-440. German.

35. Kurisu S, Sato H, Kawagoe T, et al. Tako-tsubo-like left ventricular dysfunction with ST-segment elevation: a novel cardiac syndrome mimicking acute myocardial infarction. Am Heart J. 2002;143(3): $448-455$. 
36. Abe Y, Kondo M, Matsuoka R, Araki M, Dohyama K, Tanio H. Assessment of clinical features in transient left ventricular apical ballooning. J Am Coll Cardiol. 2003;41(5):737-742.

37. Ueyama T, Kasamatsu K, Hano T, Yamamoto K, Tsuruo Y, Nishio I. Emotional stress induces transient left ventricular hypocontraction in the rat via activation of cardiac adrenoceptors: a possible animal model of 'tako-tsubo' cardiomyopathy. Circ J. 2002;66(7):712-713.

38. Pierpont GI, DeMaster EG, Cohn JN. Regional differences in adrenergic function within the left ventricle. Am J Physiol. 1984; 246(6 Pt 2):H824-H829.

39. Mori H, Ishikawa S, Kojima S, et al. Increased responsiveness of left ventricular apical myocardium to adrenergic stimuli. Cardiovas Res. 1993;27(2):192-198.

40. Khurana RK. Takotsubo cardiomyopathy in a patient with postural tachycardia syndrome. Clin Auton Res. 2008;18(1):43-47.

41. Silbernagl S, Lang F. Taschenatlas der Pathophysiologie [Color atlas of pathophysiology]. Stuttgart: Thieme; 1998:217-220.

42. Carney RM, Freedland KE, Veith RC. Depression, the autonomic nervous system, and coronary heart disease. Psychosom Med. 2005;67 Suppl 1: S29-S33.

43. Lett HS, Sherwood A, Watkins L, Blumenthal JA. Depression and prognosis in cardiac patients. In: Steptoe A, editor. Depression and Physical Illness. Cambridge: Cambridge University Press; 2007:87-108.

44. Sullivan M, LaCroix A, Russo J, Swords E, Sornson M, Katon W. Depression in coronary heart disease. What is the appropriate diagnostic threshold? Psychosomatics. 1999;40(4):286-292.

45. Dickens C, McGowan L, Percival C, et al. New onset depression following myocardial infarction predicts cardiac mortality. Psychosom Med. 2008a;70(4):450-455.

46. Bekke-Hansen S, Trockel M, Burg MM, Taylor CB. Depressive symptom dimensions and cardiac prognosis following myocardial infarction: results from the ENRICHD clinical trial. Psychol Med. 2012;42(1): $51-60$.

47. Krzyzkowiak W. Depression after myocardial infarction and its psychosocial conditions. Psychiatr Pol. 2007;41(5):679-691. Polish.

48. Robichaud-Ekstrand S. The anti-depressive effects of post-infarct exercises. Can Nurse. 1992;88(6):41-44. French.

49. Dickens C, McGowan I, Percival C, et al. Negative illness perceptions are associated with new-onset depression following myocardial infarction. Gen Hosp Psychiatry. 2008b;30(5):414-420.

50. de Jonge P, Mangano D, Whooley MA. Differential association of cognitive and somatic depressive symptoms with heart rate variability in patients with stable coronary heart disease: findings from the Heart and Soul Study. Psychosom Med. 2007;69(8):735-739.

51. Lane DA, Chong AY, Lip GY. Psychological interventions for depression in heart failure. Cochrane Database Syst Rev. 2009;(1):CD003329.

52. Kapfhammer HP. Der Zusammenhang von Depression, Angst und Herzerkrankung - Eine psychosomatische Herausforderung [The relationship between depression, anxiety and heart disease - a psychosomatic challenge]. Psychiatr Danub. 2011;23(4):412-424. German.

53. Guarneri E, Horrigan BJ, Pechura CM. The efficacy and cost effectiveness of integrative medicine: a review of the medical and corporate literature. Explore (NY). 2010;6(5):308-312.

54. Scherrer JF, Gartfield LD, Lustman PJ, et al. Antidepressant drug compliance: reduced risk of MI and mortality in depressed patients. Am J Med. 2011;124(4):318-324.

55. Dowlati Y, Herrmann N, Swardfager WL, Reim EK, Lanctôt KL. Efficacy and tolerability of antidepressants for treatment of depression in coronary artery disease: a meta-analysis. Can J Psychiatry. 2010;55(2): 91-99.

56. Baumeister H, Hutter N, Bengel J. Psychological and pharmacological inteventions for depression in patients with coronary artery disease. Cochrane Database Syst Rev. 2011;(9):CD008381.
57. Benkert O, Hippius H. Kompendium der Psychiatrischen Pharmakotherapie [Compendium of psychiatric pharmacotherapy]. 8th ed. Springer-Verlag: Heidelberg; 2011. German.

58. Himmerich H, Fulda S, Schaaf L, Beitinger PA, Schuld A, Pollmächer T. Changes in weight and glucose tolerance during treatment with mirtazapine. Diabetes Care. 2006;29(1):170.

59. Licht CM, Penninx BW, de Geus EJ. Effects of antidepressants, but not psychopathology, on cardiac sympathetic control: a longitudinal study. Neuropsychopharmacology. 2012;37:2487-2495.

60. van Haelst IM, van Klei WA, Doodeman HJ, Kalkman CJ, Egberts TC; MAOI Study Group. Antidepressive treatment with monoamine oxidase inhibitors and the occurrence of intraoperative hemodynamic events: a retrospective observational cohort study. J Clin Psychiatry. 2012;73(8): 1103-1109.

61. Bishara D, Taylor D. Asenapine monotherapy in the acute treatment of both schizophrenia and bipolar I disorder. Neuropsychiatr Dis Treat. 2009;5:483-490.

62. Croxtail JD. Aripiprazole: a review of its use in the management of schizophrenia in adults. CNS Drugs. 2012;26(2):155-183.

63. Benkert O. StressDepression: Die neue Volkskrankheit und was man dagegen tun kann [Stress depression: the new disease of the people and what you can do about it]. CH Beck: München; 2009. German.

64. Deuschle M, Schneider F. Psychokardiologie [Psychocardiology]. In: Schneider F, editor. Facharztwissen Psychiatrie und Psychotherapie [Specialist psychiatry and psychotherapy]. Springer-Verlag: Heidelberg; 2012:489-493. German.

65. Schroeder C, Jordan J. Norepinephrine transporter function and human cardiovascular disease. Am J Physiol Heart Circ Physiol. 2012;303: H1273-H1282.

66. Pringle A, McCabe C, Cowen P, Harmer C. Antidepressant treatment and emotional processing: can we dissociate the roles of serotonin and noradrenaline? J Psychopharmacol. 2013. Epub Feb 7.

67. Thompson C, Syddall H, Rodin I, Osmond C, Barker DJP. Birth weight and the risk of depressive disorder in late life. Brit J Psychiatr. 2001;179:450-455.

68. Ako J, Takenaka K, Uno K, et al. Reversible left ventricular systolic dysfunction - reversibility of coronary microvascular abnormality. Jpn Heart J. 2001;42(3):355-363.

69. Amore M, Innamorati M, Costi S, Sher L, Girardi P, Pompili M. Partial androgen deficiency, depression, and testosterone supplementation in aging men. Int J Endocrinol. 2012;2012:280724.

70. Behrens CB, Nef HM, Hilpert P, et al. Major depression as a potential trigger for Tako Tsubo cardiomyopathy. Int J Cardiol. 2010;140(2):e40-e42.

71. Himmerich H, Schneider F. Psychoneuroendokrinologie [Psychoneuroendocrinology]. In: Schneider F, editor. Facharztwissen Psychiatrie und Psychotherapie [Specialist psychiatry and psychotherapy]. Springer-Verlag: Heidelberg; 2012:495-501. German.

72. Jiang W. Impacts of depression and emotional distress on cardiac disease. Cleve Clin J Med. 2008;75 Supp1 2:S20-S25.

73. Johnson MR, Lydiard RB, Morton WA, et al. Effect of fluvoxamine, imipramine and placebo on catecholamine function in depressed outpatients. J Psychiatric Res. 1993;27(2):161-172.

74. Kurisu S, Inoue I, Kawagoe T, et al. Myocardial perfusion and fatty acid metabolism in patients with tako-tsubo-like left ventricular dysfunction. J Am Coll Cardiol. 2003;41:743-748.

75. Lederbogen F. Psychopharmaka bei Herzerkrankungen [Psychotropic drugs for heart disease]. Herz Heute. 2008;4:20-25. German.

76. Licht CM, de Geus EJ, Seldenrijk A, et al. Depression is associated with decreased blood pressure, but antidepressant use increases the risk for hypertension. Hypertension. 2009;53(4):631-638.

77. Scherrer JF, Chrusciel T, Lauren D, et al. Treatment-resistant and insufficiently treated depression and all-cause mortality following myocardial infarction. B J Psychiatry. 2012;200:137-142. 
Research Reports in Clinical Cardiology

Dovepress

\section{Publish your work in this journal}

Research Reports in Clinical Cardiology is an international, peerreviewed, open access journal publishing original research, reports, editorials, reviews and commentaries on all areas of cardiology in the clinic and laboratory. The manuscript management system is completely online and includes a very quick and fair peer-review system.

Visit http://www.dovepress.com/testimonials.php to read real quotes from published authors.

Submit your manuscript here: http://www.dovepress.com/research-reports-in-clinical-cardiology-journal 